\title{
Research on Mass Aesthetic Consciousness ---From the Perspective of Light Image Development
}

\author{
Guodong Hou ${ }^{\mathrm{a}}$, Ying Du ${ }^{\mathrm{b}}$ \\ Wuhan Huaxia University of Technology, Wuhan 430223, China. \\ a44931559@qq.com, b771217051@qq.com
}

\begin{abstract}
With the development of digital technology, photographic model of light images, as an important media of recording and broadcasting, has integrated, into daily life for common people.The growth of light images adds more colors to the blooming of photographic culture. On the other hand, its growth is confined to photographic aesthetics. The thesis analyses the aesthetic issues of light images, attempts to provide a guideline and cultivate mass aesthetic consciousness and taste after illustrating the features of mass photography and social media.
\end{abstract}

Keywords: Light Images; mass photography; aesthetics.

\section{基于轻影像嬗变的大众审美意识研究}

\author{
侯国栋，杜英 \\ 武汉华夏理工学院
}

摘 要: 随技术的发展, 轻影像摄影模式成为大众生活的一部分, 成为影像记录、传播的重要 媒介着数字和手段。轻影像的发展繁荣了摄影文化, 但是又受制于影像审美。本文分析了轻 影像带来的审美问题, 结合大众摄影和社交媒体传播的特征提出了营造大众审美意识和审美 趣味的方向和方法。

\section{关键词：轻影像 大众摄影 审美}

\section{1. 前言}

摄影的发展与传播媒介的发展密不可分, 数字摄影更是如此。社交媒体崛起后大众摄影的物 质形态、艺术形态、文化形态都发生了深刻的变化。近年来由于摄影功能的不断完善, 智能 手机已经成为使用人数最多的摄影器材。除了方便快捷的摄影和修图外, 智能手机的另一个 优势是与社交媒体绑定, 可以快速的发布、反馈影像。

这种利用手机、平板电脑等智能设备拍摄、处理影像并通过社交媒体即时发布和讨论图片的 摄影模式, 就是轻影像。随着技术进步, 轻影像模式也在不断变革, 日益深入人心, 目前全 球照片储存总量以兆为单位计算, 其中约 78.8\%来自手机。然而, 大众摄影的发展与摄影美 学和大众审美的发展不同步, 大众影像的品质提升有限, 优质照片数量没有快速的增长。

\section{2. 轻影像成为大众摄影的重要模式}

摄影术自诞生以来一直属于精英艺术，技术壁垒和媒介壁垒是制约其大众化的两个障碍，这 一局面直到数码影像技术出现才有所改变。轻影像的拍摄方式有多方面的优势彻底打破了这 两个壁垒。

首先, 轻影像具有随拍性的特点。随拍性在当代摄影特别是新闻摄影中得到了越来越广泛的 应用和认同。伦敦地铁爆炸案、2009 年哈德孙河飞机迫降等重大事件发生后, 现场有人用手 机拍摄了图片, 并发表在各大媒体, 这都是轻影像的标志性事件。 
其次，轻影像将前期拍摄与后期处理集成于同一设备，各式各样的 APP 应用可以及时快捷的 提供各种服务。这种后期方式操作简单上手快, 不需要专门学习, 操作界面可视化程度非常 高，更容易被大众接受。

第三, 社交媒体的发展赋予了拍照更多的意义, 如今人们对于分享的渴望已经大过了记录和 审美上的需求。一份研究显示, 每天拍摄然后分享照片能够从多个层面对我们的身心健康产 生有益的影响，其中包括通过线上互动减少孤独感、增加运动量、挖掘回忆的潜力等。

轻影像快速发展给人们带来了几何级数增长的影像, 数据显示 $81.5 \%$ 的微博用户偏好图片加 文字, 50.7\%的微信用户朋友圈内容形式偏好为图片, 今日头条组图内容的阅读量占比从 2016 年年初的 $7.3 \%$ 增至 2016 年 10 月的 $16.5 \%$, 图片仍将是自媒体今后最重要的内容表达形式。

\section{3. 轻影像快速发展凸显了大众审美的问题}

3. 1. 轻影像的低门槛带来审美准备不足

经济发展、人民生活水平提高、数码科技和数字技术进步, 都是轻影像产生的条件。美国机 构 Zenith 发布的研究报告指出, 2018 年中国智能手机用户数量将达到 13 亿，是 2011 年数 据的 8 倍, 急速增长的人群都是潜在的轻影像摄影师。

社交媒体图片数量剧增的时间与智能手机用户剧增的时间基本同步，这种快速增长促进了大 众摄影的繁荣和全民摄影师时代的到来, 也反映出了全社会和大众对轻影像的到来准备不足, 大众审美意识和审美能力不足以应对海量的图片信息, 导致了大众摄影在审美追求上的滞后。 3.2. 大众摄影流于形式，娱乐化、低俗化、碎片化倾向严重

大众艺术繁荣的同时也是对视觉艺术的消减, 大众摄影因失去提升品位的方向而流于俗套。

《在文艺工作座谈会上的讲话》中对艺术领域的问题做了批判, 指出 “存在着抄袭模仿、千 篇一律的问题，存在着机械化生产、快餐式消费的问题”，这些问题在大众摄影领域也比较 突出。

由于个体审美意识不足, 缺乏审美教育和引导，大众在摄影审美上容易拘泥于 “形式” ，往 往比较看重视觉冲击力强的画面, 将 “形式美” 等同于 “摄影美”。大众审美水平发展缓慢, 出现了以 “丑” 为美, 以“娱乐” 为目的, 一味媚俗、低级趣味的倾向。

智能手机和社交媒体打破了信息壁垒，同时也将信息分割成为各种碎片，在网上不断的流动 和改写。碎片化的审美制约了摄影的原创力和创造力, 大众在摄影创作中缺少独立思考, 过 度模仿，导致摄影作品同质化现象严重。

3. 3. 摄影作品内涵缺失，亲切感和陌生感缺失

美产生于审美过程中, 美是动态的、过程性的, 触发审美的事物必须引起人们足够的主观注 意力, 产生新鲜感, 美学上称之为陌生感。据腾讯公司统计, 每天在微信朋友圈和 $\mathrm{QQ}$ 空间上 传的图片高达 10 亿张。这就意味着每天有大量的照片不会被逐一细看, 更不会被审美, 从而 成为视觉垃圾。

美感是一种心理感受, 除了陌生感还应该有亲切感, 亲切感是建立在陌生感之上的, 陌生感 有待于发展为亲切感。受众不会在完全没有经验支持的状态下去理解和欣赏艺术作品。目前 在社交媒体传播的照片中，有非常多的照片缺乏亲切感，如自拍、“晒娃”等。

基于这两种原因, 不具备美感的照片可以分为几类: 脱离生活和受众, 缺乏亲切感; 图片的 描述方式过于直白, 缺乏陌生感, 不能引起观看者的注意、思考和判断; 图片既没有亲切感 也没有陌生感。

\section{4. 营造大众摄影的审美意识和审美趣味}

研究摄影美学, 最主要的是能够解决摄影中存在的问题, 通过分析轻影像带来的审美不足, 因势利导的提出解决方案。在轻影像模式, 大众普遍参与摄影, 创造了丰富的摄影作品, 但 
是优秀作品的数量并没有相应提升, 这折射出大众的摄影审美不足。从美学的角度考量, 需 要从多个方面开展摄影审美, 提升作品的品质。

4. 1. 摄影作品能引起欣赏者的注意, 引发观察、思考和判断

轻影像将摄影作品的观看方式推上了新的高度, 拍摄者多种渠道的展示照片, 带来了互联网 和社交媒体的审美方式。新的观看方式决定了观众不会在一幅照片上停留太长的时间, 庞大 的照片数量也决定了观众不可能观看所有的照片, 所以摄影作品要想获得更佳的审美效果, 首先要引发观众注意。

观众在对照片的关注和思考中实现审美价值和审美过程的动态对应。不能引起观众持久注意 的对象与美无关, 越是受关注的照片越具备审美价值。摄影创作中, 要侧重营造另一世界, 引起观众的思考和判断。

4. 2. 摄影作品能引起观者的共鸣, 在图片世界中找到自我

摄影是一面有记忆的镜子, 在这面镜子里人们能够看到自己的影子。李普斯认为, 审美享受 是一种客观化的自我享受。审美享受就是在一个与自我不同的感性对象中自我娱乐的本身, 即把自我融入到对象中去。简单来说, 审美就是在审 “自我” , 发现对象中的自我, 优秀的 摄影作品能让观众找寻到自己的影子, 能触动心灵, 从而取得极大的认可。

4. 3. 通过对日常视觉经验的否定来获得陌生感

日常生活的重复给人们带来了视觉疲劳, 陌生感不断弱化, 审美趣味越来越低, 往往可以通 过否定日常视觉经验来获得更好的美的享受。常见的否定方式有以下几种。

空间的否定，即否定日常生活的区域寻求另一现实存在的区域。如同人们旅游一样，到另一 个不熟悉的地方拍摄照片, 来寻求陌生感。在大众摄影中, 空间的否定是最常见的一种, 很 多人创作的峰值空间往往是在旅行、出差的区域, 而不是在自己生活的区域。时间的否定, 即否定当下生活的时间, 最为典型的就是对历史照片的回顾。人们在欣赏老照片的时候, 会 对曾经熟悉的人物和环境产生新的陌生感, 因而开始新的审美。感觉的否定, 即否定日常的 视觉体验, 借助工具来获得新的视觉感知。比较常见的有通过镜头的焦距、景深的控制等技 巧和器材的使用来获得。

因此在摄影创作中, 可以将日常视觉经验的否定作为提升摄影审美的一个手段。如拍摄于 1957 年的经典名作《牛奶皇冠》, 虽然被摄体非常常见, 但是展示的视觉效果却非常奇特, 打破 了人们的日常视觉经验, 因此受到了极大的欢迎, 时至今日仍然有大批的人在重复拍摄这一 场景。

4. 4. 摄影作品要具备陌生感与亲切感的统一

美不是对象的固有属性，而是欣赏者主观发现、转化、创造的结果，随时间、场所、心境而 变。摄影作品具有自我实现的媒介功能, 是自我实现的载体, 观看者在欣赏作品的过程中才 会有审美，通过判断才会产生价值。

在关注摄影作品的时候, 最基础的感受是新鲜感、陌生感, 进一步的美感会成为一种亲切感 和归属感。陌生感是亲切感的基础, 必将发展为亲切感, 这样才会有很好的美感体验。任何 一方面的缺失, 都将极大的影响摄影审美。摄影作品要让受众有亲切感, 就必须抓住受众的 生活经验和审美经验, 使其能够找到熟悉的元素并引起共鸣。

不同的文明阶段和观念下, 美的形态是不一样的。明代画家石涛有 “笔墨当随时代” 的名言, 这句话放在当代仍然是正确的, 摄影创作、审美必须与这个时代相结合, 与当代的社会、经 济、文化相呼应。摄影审美首先是当代人的审美, 陌生感和亲切感必然依托于今人的判断。

\section{Acknowledgements}

Research on Enhancement of Mass Photography and Mass Aesthetic Awareness---from the Perspective of Social Media.Humanities and social sciences research project from Ministry of education of Hubei Province. Program No: 15G209. 


\section{References}

[1]. Qian Zhang, Jingling Lv. Introduction to Art Aesthetics [M], Peking University Press, 2016.

[2]. Yuan Gong. Discussion on photography culture under the condition of digital media technology [J].Oriental Enterprise Culture. (2017) No. S2, p24.

[3]. Yanbu Zhang. Technological Exploration and Aesthetic Objective of Virtual Cinematography [Contemporary Cinema. (2017) No. 5, p141-144.

[4]. Zhen Grong Deng. A brief discussion on the unique aesthetics of photography [J].Art Evaluation. (2017) No.23, p185-187.

[5]. Aioli Wu. The unique aesthetic appeal of photography art [J].Popular Culture\& Arts. (2017) No. 24, p137-138. 